\title{
Management control in startups with high growth success in the Technology sector: The case of Netrivals
}

\author{
Dolors Celma \\ Tecnocampus - Universitat Pompeu Fabra \\ Marian Buil \\ Tecnocampus - Universitat Pompeu Fabra \\ Josep Patau \\ Tecnocampus - Universitat Pompeu Fabra
}

Received May 14, 2017; accepted May 28, 2017.

\begin{abstract}
The objective of this article is to analyse the use of financial and non-financial indicators by the NetRivals Company and its importance for the control of business management. Ultimately, it is intended to design a strategic map of the company together with a Balanced Scorecard (BSC) that serves to identify the critical success factors and Key Performance Indicators (KPI) that allow an optimal tracking and analysis of its functioning for decision making. An empirical methodology based on a case study is used. The descriptive analysis of an experience of implementing the BSC in an internet company will be used as well as an exploratory study that formulates the key factors of success and sectoral indicators of this type of companies which will be tested in later studies. Firstly, the study will be checked whether NetRivals has the key success factors and generic KPIs recorded in the four perspectives of BSC. Secondly, the specific key success factors and KPIs for NetRivals will be determined and its strategic map defined. Added value light will be shed on the key success factors and KPIs of companies that operate entirely on the Internet, and particularly SMEs with high growth in a highly competitive sector.
\end{abstract}

\section{KEYWORDS}

Internet companies, Balanced Scorecard, key success factor, Key Performance Indicator JEL codes: M13, M15 


\section{Introduction}

According to the Spanish Report, CONECTA (Alvarez et al., 2011), prepared by Boston Consulting Group at the request of Google, Internet businesses accounted for $2.2 \%$ of GDP in 2009 and were expected to multiply their impact by 2.7 in 2015 . In addition, more than three quarters of GDP is generated in sectors where the Internet is transforming key business processes such as purchasing, marketing or final sales.

Netrivals has been selected as the object of study of this article within the sector of Internet companies.

NetRivals is a technological startup located in the Technology and Innovation Park, Tecnocampus, in Mataró. Its operation is based on the design of its tool NetRivals.com, an online tool that allows electronic commerce to monitor the prices of its competitors in real time and to compare them with its own by means of Big Data techniques to obtain data off the Web.

The company moves in a very competitive sector where price is the key factor. Its platform makes a more efficient use of every euro spent on marketing by its customers, e-commerce companies, since each company that uses this tool gets to know, in real time, which products are the most competitive in terms of price at any time, so that if they rely only on these a sale is more likely to be made and their money will be monetized better. In addition, the tool can also detect when the competition has run out of stock and its products are sought after by consumers, even if prices rise.

The NetRivals strategy is supported by business scalability. Since its service is defined as a SAAS (Software as a Service) it has a gross profitability of $100 \%$, that is to say that once the development of the application has been made, the business is based on selling the service as many times as possible. Therefore, NetRivals uses a market penetration strategy to achieve the highest possible sales volume of its service nationally and internationally.

Every day NetRivals.com scans its customers' servers for information about their products to be able to compare them, managing to process an average of four terabytes of data 
daily. A monitoring service takes between 24-72 hours to start monitoring the competitor's products. The first step is to inform the platform of the store that the customer wants to control. Then the technical team begins a series of tasks to deposit all the products from the competitor's website onto a structured database. Then an importer is launched, and in the end the customer can start monitoring the competitor's products.

To capture potential customers - e-commerce - there is an automated process that operates 24 hours a day, 7 days a week, which captures the new e-commerce that appears online. The electronic stores captured are stored in the company's CRM pending a manual review. Once e-commerce is validated manually, the system classifies and punctuates ecommerce, determining its competitors' map, an estimate of the organic traffic of the last 4 years, its relevance ranking on the Internet, and the e-commerce theme it is dedicated to.

It is based on the premise that the usefulness of the tool will be valid only for those customers who have more than 50 products in their catalogue, who appear in the SemRush index and have at least three competitors online.

The presentation of the service is carried out in three phases:

- Making use of the CRM, the sales team contacts the head of e-commerce via the telephone or unique and gives an initial presentation of the product, and sends a made-to-measure commercial proposal according to the needs of the customer.

- The presentation is accompanied by a demonstration in which the customer can use the tool to assess the possibilities NetRivals can offer him.

- The sales team follows up the customer and schedules future meetings to close the negotiation.

To close the sale and production order the procedure is as follows: in the case of closing the sale, the customer provides all the information necessary to be able to proceed with billing services and complements the production order, a document that defines the map of competitors which NetRivals uses to analyse competitiveness.

Finally, the billing department goes to charge the services contracted NetRivals and seen is given and approved the technical department to begin technical tasks to operate NetRivals ad hoc for the customer. 
In order to attract the products, NetRivals needs to create the capture of both the customer and the map of competitors specified in the production order. To do this task, the technical department develops the necessary robots to achieve this milestone, based on the production order provided by the customer. In this way, from the technical department generates as many robots (scripts) as are necessary to make the capture of all the articles of the competitors and thus to make sense to the tool of comparison.

The quality tracking system operates as follows: all new scripts and rewritten scripts that are transferred to the production system go through a manual quality process that verifies that the articles have been correctly obtained from the extracted data to a real approximation of the expected totality in the uptake. Due to changes that web page owners can make both structurally (website design) and in the business, the system launches different types of alerts that require manual action to verify if the system is working correctly. While it is true that NetRivals allows its customers to report errors, the system tries to detect them before the customer does and have them fixed by the technical team and thus improve the perception of service quality.

For customer loyalty, NetRivals alerts the movements in terms of the competitors' price strategies by email, and through these messages tries to get the customer to make a continuous use of the tool.

Currently NetRivals has very little competition. In Spain, no consolidated company in the monitoring of competitive prices for small businesses exists, and the only startup that has customers as "big sector" businesses that has been found is minderest.com.

On an international level there are only three companies are known:

- price2spy.com: a Serbian company with more than 20 employees and a turnover of 800,000 euros last year.

- profitero.com: a company of Irish origin and operating in the United States, has a workforce of 15 people. It is invested in by two mutual funds.

- wiser.com: a leading American company in the United States, with little presence in Europe. 
NetRivals differentiates itself from its competition by being based on the experience of its call center and the CRM with its thousands of opportunities detected and informed of.

The staff structure of consists of: a management team that performs tasks of product manager and general management; administrative staff who perform administrative tasks: a customer account, billing and support for customer withdrawals; a sales team with a sales manager and telemarketing vendors in charge of making calls to sell subscriptions to NetRivals; a team of technicians who develop the scripts to obtain the products from each electronic trade; a quality control team that checks the system's automatic alert system and establishes if there have been any errors or false alarms. It also reviews the quality of the imports products; and finally, they are the ones in charge of design.

As for the estimated forecast in the economic-financial plan of the company in 2015, NetRivals estimates that the business is profitable provided that sales do not fall from a $57 \%$ that hitherto estimated (or translated to the number of monthly sales, coming to less than 43). Thus, the company has to achieve sales of more than $€ 768,643$, or putting it another way, ending each year with a customer portfolio of 1,500 between registrations and renewals.

To achieve its sales targets, the company has estimated a holding capacity of 70 customers per month from the company Bueni (an online article comparator owned by the same partners as NetRivals) with a fee of $€ 225$ and a minimum of 20 Sales to new customers with a monthly fee of $€ 600$. In addition, it is estimated that it is necessary to ensure customer loyalty for at least three years.

After reviewing the internal and external context of the company NetRivals, the aim of this study is to analyse the use of financial and non-financial indicators on behalf of the company and its importance for the control of business management. Ultimately it is intended to design a strategic map of the company together with a Balanced Scorecard (BSC) that serves to identify the critical success factors and Key Performance Indicators (KPI) that allow an optimal monitoring and analysis of its functioning for decision making. For this the following research questions have been asked: 
1. Does Netrivals have the key success factors and the registered generic KPIs in the four perspectives of a BSC?

2. Are there key success factors and specific KPIs for a high-growth technological startup such as NetRivals?

3. What is the strategic map and the BSC of the company Netrivals?

\section{Literature review}

\subsection{The Balanced Scorecard as a management tool}

The way to manage and control an organization has undergone a remarkable evolution in the last 30 years (Monte and Fontenete, 2012). The new management tools developed as a result of the adaptation of companies to new times have impelled a boost and a renewal of the way in which organizations are managed. It is worth mentioning the role developed by the integral scorecard as a spearhead of these new tools (Naqi, 2013).

The scorecard or Balanced Scorecard developed by Kaplan and Norton (1992) emphasizes the need to incorporate a less financial and more strategic management control perspective, adding to the usual qualitative indicators of financial performance information. To this day, the BSC is one of the management tools which is most used by organizations. According to the latest annual report by Bain \& Company Corporation (Rigby and Bilodeau, 2011), the BSC ranks as one of the five most popular management tools and even estimates a global use of 63 percent by companies. This tool was designed by its creators in order to correct some of the shortcomings and inaccuracies of previous managerial approaches. In this sense, Kaplan and Norton tried to provide organizations with a clear pattern of what to measure and manage. The BSC is a very useful tool to synthetically manage a large amount of information that helps a manager in the decision-making process.

In order to design a BSC it is necessary to have a strategic plan of the company. Working from the strategic plan, key success factors are designed and will be monitored through indicators. Key success factors can be both internal and external; both financially and non-financially (Kaplan and Norton, 1992). We are therefore faced with a management tool that synthesizes key information for the company and forces managers and managers 
to consider a strategy: BSC is clearly linked to the achievement of long-term strategic objectives (Figure 1).

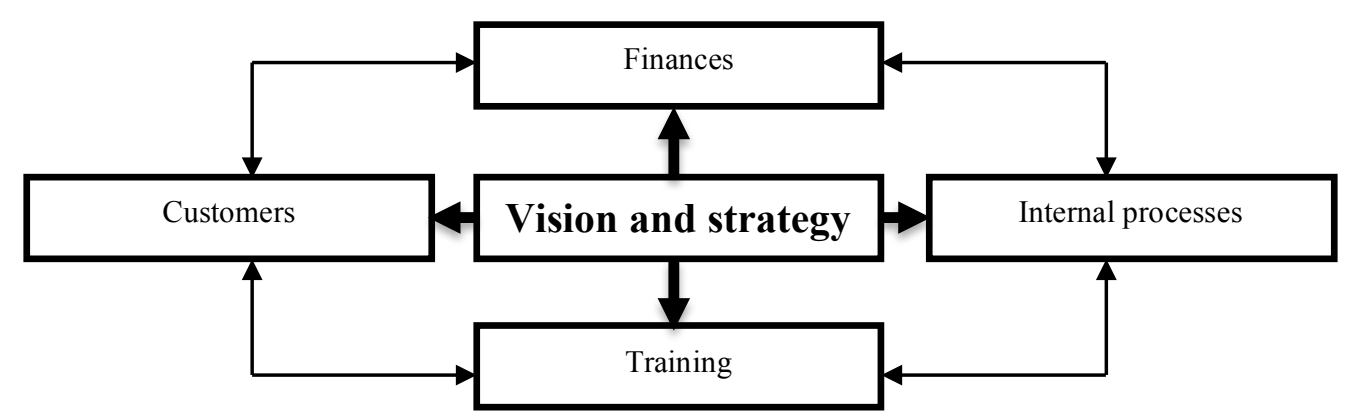

Figure 1. Structure of the BSC showing the transformation of the strategy into operational terms (adapted from Kaplan and Norton, 1992)

According to Kaplan and Norton (1992) the controlling the key success factors must fit into the so-called four BSC perspectives: financial, customer, internal processes and training and growth. This novel vision allowed the authors to establish a balance between the short and long term objectives and to coordinate the different functional areas to achieve a common goal: to achieve the objectives marked by the integrated strategy of the organization. In addition, for each perspective not only must the key success factors and its corresponding indicators be identified, but also the cause-effect relationships that explain and determine how to achieve better results. This defines the company's strategic map, which is a graph providing an image of the key success factors and the relationships between them, so that the causality of these relations is graphically visualized (Figure 2). 
Finances

Customers

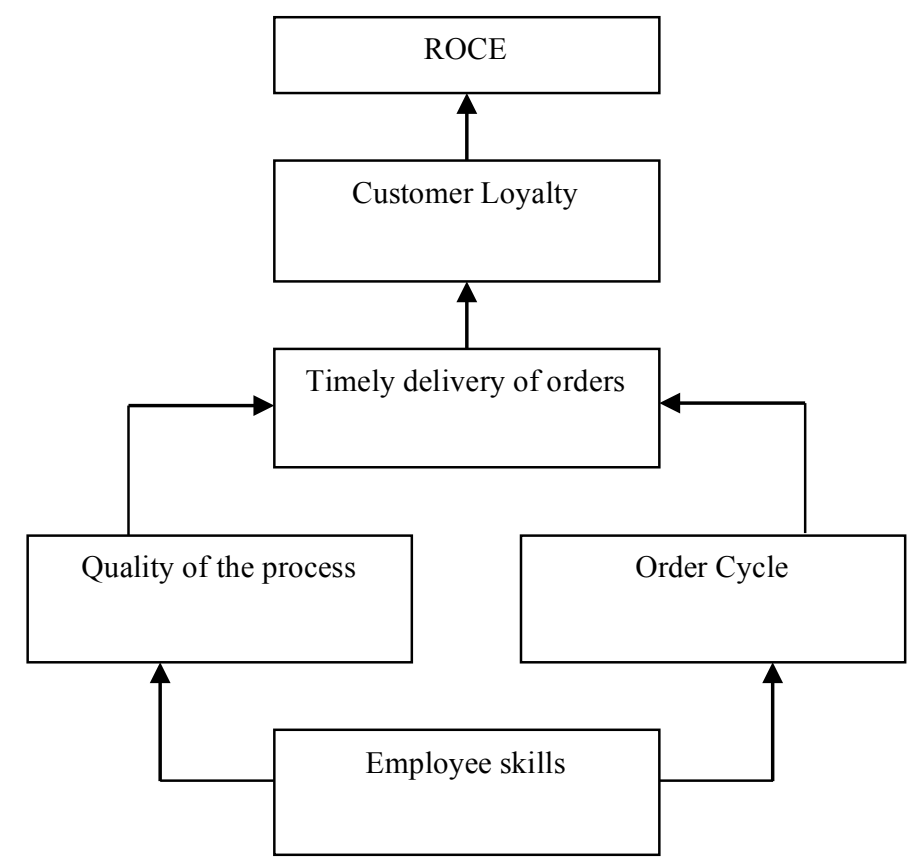

Figure 2. Example of the 4 perspectives and the chain incorporating some key factors for each perspective (Kaplan and Norton, 1992)

From the strategic map we can define the indicators of measurement or Key Performance Indicators for each of the key success factors, which will be the ones that will allow control and monitoring of the objectives established by the company to be carried out and therefore the success of its management.

The BSC can be used to control the whole organization or smaller organizational units, such as the typology of the different departments, while being used to coordinate the actions of each of these units to align the objectives of all the departments in the same direction: the achievement of the overall objectives of the organization. Other uses of the BSC are encouragement, an incentive in the case of achieving the objectives, providing feedback to the managers of the organization or assessing the effectiveness, efficiency and quality of the management by the heads of the lower units which form an organization. 


\subsection{Balanced Scorecard and Small Business}

Although the BSC can be implemented in any type of company, regardless of its size, the analysis of the effect of implementing this type of tool in SMEs is scarce in the literature available (Rompho, 2011).

However, the few studies that do exist suggest that the use of BSC in small and mediumsized enterprises (SMEs) is not widespread (Tennant and Tanoren, 2005). Similarly, Rigby and Bilodeau (2011) cite the difference between the use of management tools between large and small companies by 30 percent and with a tendency for the difference to be increasing, justifying this trend in the resources needed to manage a BSC and in the economic downturn.

Other authors argue that it is difficult to involve SMEs in performance measurement projects because of the lack of time available, the lack of involvement of senior managers, and the fact that informal SME controls are more commonly used in SMEs James, 2000). Despite the fact that most of the literature certifies the use of informal systems in the SMEs, it is also true that formal systems like BSC increase in use to a greater degree of complexity, competition and rapid evolution of the sector. Thus, what a normal SME can control with sight, hearing or smell, will hardly be controllable in sectors such as the Internet where parameters evolve continuously and where speed of adaptation to the demand and environment are key to the Survival (Pozo and Correa, 2000).

\subsection{Adaptability of the Balanced Scorecard}

Various authors have defended the possibility of adapting the IMC proposed by Kaplan and Norton (1992) to the typology of a company responding to its mission and vision as well as to the objectives set.

To do this, in a first phase, it is necessary to establish the number and type of perspectives of the company's BSC and, in a second phase, the order established between them in order to create a logical sequence of cause and effect relationships (Amat et al., 2001) and choose the indicators that will control the achievement of the target marked in each established perspective.

Kaplan and Norton (2002) argue that a good BSC is the representation in a coherent structure of the business strategy through objectives clearly intertwined with each other, 
measured with indicators that pursue certain commitments and are supported by a set of initiatives and projects. In turn, Ballarin and Davila (1999) stress that working with a business model and translating it into indicators facilitate consensus across the organization and clarify how day-to-day actions affect not only the short term but also the long term.

Amat et al. (2001) talks about the factors that drive the growth of the Catalan gazelle companies and defines their key factors for each of the perspectives to follow in order to be able to elaborate a specific IMC for this type of company. For Catalan gazelle companies the critical success factors are related to human factors. These companies opt for the training of and incentives for employees in order to have an impact on greater market orientation and customer satisfaction. In order to respond to this, it is necessary to improve internal processes and, in this way, allow higher sales to be generated, which would have a greater impact on the company.

Voelker et al. (2001) propose a pyramidal representation of pro-profit organizations and compare it with non-profit organizations. They state that depending on the nature of the companies, a BSC structure can be drawn which includes the four perspectives along a bottom line in which they are interrelated and oriented towards the business strategy. In the case of pro-profit entities, it is customary to put finances at the top, given that the maximization of the firm's value is the ultimate goal. Thus, the achievement of perspectives as well as the indicators of each one of the perspectives put forward in this case are: at the bottom, the perspective of people (infrastructure of personnel available) to create value which will contribute to the accomplishment of internal processes carried out to satisfy the customers and all this to achieve the financial goals of the company. In contrast, for non-profit organizations, the users of the products / services or the global society are usually located at the top. Therefore, the perspective of people (staff infrastructure available) to create value, which will contribute to the implementation of internal processes financed by providers of financial resources, is proposed in this case so that all of this ultimately has an optimal impact on stakeholders or involved in the process of non - profit organizations.

Cebrián and Cerviño (2004) propose an adapted BSC for the case of sanitary entities. In this case the mission focuses on the sustainability of health care that is made up of social, 
economic and environmental sustainability, responding to the satisfaction of both patients and physicians and insurance entities of health products. This can be summarized by: Learning (firstly, if the necessary conditions for an adequate knowledge management are available); Growth (afterwards if adequate and flexible infrastructure is available to adapt to the competitive and changing environment in areas of sustainable knowledge); Internal processes (they then ask themselves about the processes necessary to satisfy the patient); Financial (analysing suppliers and economic-financial conditions); and stakeholders (observing patients, doctors and health insurance entities).

In the present case, Dubelaar et al. (2005) summarize the most important critical success factors for e-business firms proposed by previous authors (Phan, 2001, Turban et al., 2000, Porter, 2001 and Butler, 2000) and group them into three types of factors: strategic factors, structural factors and management factors (Table 1).

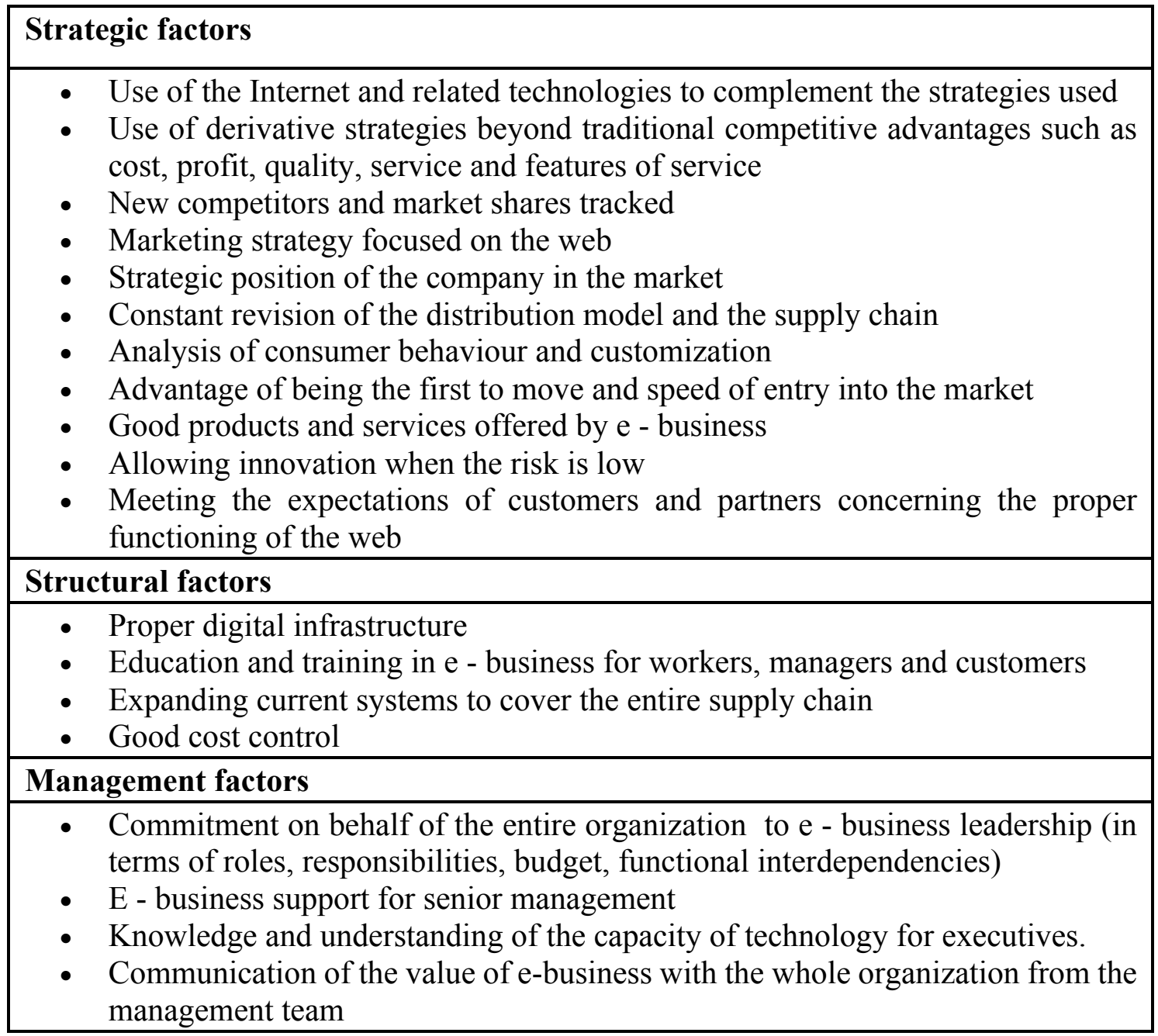

Table 1. Main e-business success factors identified by the literature (adapted from Dubelaar et al., 2005) 
In light of what has been described in the previous sections, and given the growing importance of the e-business sector, the main goal of this study is to propose a strategic map and a balanced scorecard that allows monitoring and follow-up of the degree of fulfilment of the goals set in the strategy of an Internet company, in this case of the company NetRivals. This study aims to shed light on the critical success factors and KPIs of small companies that, like NetRivals, operate entirely on the Internet, and thus have a model to study the extrapolation of these indicators to companies in the sector.

\section{Methodology}

For the elaboration of this article we have use an empirical methodology, and more specifically the so-called case study, to achieve the objectives set. Yin (1989) defines the study of the case as "an empirical investigation that studies a contemporary phenomenon in its real context aimed at understanding certain dynamics present in singular contexts". In our study, it is a question of analysing the adaptability and success of a typical business management model, the balanced scorecard, to a singular context of how a company operates entirely on the internet, and more specifically, a successful SME High growth.

With the study of the case of the company, NetRivals not only seeks to analyse the model itself, but also to detect the variables that have had a key part in the implementation and success of the model of the company present.

Within the methodology of the case study (Yin, 1989) there are different variants depending on the objectives pursued:

- Descriptive studies: those that are intended to describe the object of study in as detailed a manner as possible.

- Exploratory studies are those that are developed when there is a very high degree of uncertainty and contemplate pilot studies to try to formulate questions or hypotheses to be tested at a later date as precisely as possible.

- Explanatory studies: those characterized by answering questions of how and why.

It could be said therefore that the present study is a combination of the first two: 
- Descriptive study that attempts to maximum possible detail to describe an experience of implantation of a BSC in environments that evolve very quickly and there are highly competitive.

- Exploratory study, in the sense of trying to formulate as precisely as possible questions or hypotheses to be tested in subsequent studies (key success factors and sectoral indicators of this model).

To collect all the information that is described in the results section, a semi-structured interview was conducted, based on a questionnaire, where different people from the organization were interrogated, with the capacity of making decisions, on the general opinion of the applied model, utility Of the information derived from the indicators, the degree of validity given to this information, the degree of knowledge of the model and, indirectly, the key variables of success or failure of the model. In the assumption, we are trying to analyse the adaptability of a typically business model to a singular context of what an Internet company is like, and more specifically, a high growth SME.

Although it is still working on improving model by the company, the results have revealed certain key variables that are revealed in the success of the organization. They are separated to study these key factors into two main groups:

- Tool generics (as defined originally by the creators of the BSC in each of its 4 perspectives).

- Specific to the sector and organization (differential success factors to be controlled).

\section{An analysis of results and implications}

A questionnaire containing two sections was used to obtain information through semistructured interviews: the first referred to the use of BSC by the company and the second referred to the financial and non-financial company which is currently being used. In this second section those responsible were requested to rate the importance of the use of certain KPIs related to the four standards prospects for BSC. Those responsible were also asked to complete the list of KPIs with those who had not appeared and that they 
considered necessary to introduce the characteristics of the company and / or sector Internet companies. You can see the results of the questionnaire in Annex 1.

The most relevant data obtained from the first part of the questionnaire on the use of BSC by the NetRivals company can be summarized as follows:

- The company is currently implementing a BSC funded by the internal resources of the company. It registers different performance indicators from time to time, although it has not formally established a BSC or a strategic map due to lack of time and resources at the beginning of its business life.

- The main reasons why the company planned to establish a BSC have to do mainly with the fact of facilitating the integration of the company's strategy with the financial plans, as well as increasing the number of indicators. Those in charge in the company added a third reason in this section which initially had not been foreseen in the questionnaire), which states that the main reason for establishing a BSC in its company was to be able to control the productivity of each department and thus use the BSC as a tool card for the accountability of each person in charge.

- Those in charge at NetRivals did not show any major objection to which could prevent the implementation of BSC in the company.

- Concerning the prospects that the company considers important to record in its $\mathrm{BSC}$, it is worth highlighting, giving maximum importance, the financial perspective and the customer perspective. The specific perspective of the shareholders is currently not being contemplated as they consist of only the two founder partners and there are no foreign capitalists. The internal process perspective, the perspective of innovation and the perspective of competition are given medium importance. The perspective of suppliers, along with the prospects of workers and training are given a low level of importance (given that in the latter case, it has been shown to be unnecessary as only previously trained to a high level to develop the skills needed by the company are chosen).

In the second part of the questionnaire the use and importance of certain KPIs related to the four standards prospects of BSC by the company NetRivals was assessed as well as the proposal of new indicators for the specific needs of the company and / or the sector of internet business. 
The results regarding the KPIs used by the company NetRivals in each of the prospects and its importance can be summarized as follows:

\section{$\underline{\text { Financial perspective }}$}

NetRivals company uses the majority of classic indicators of financial performance under a standard BSC, except for the sales of new services (because only one service is commercialized); nor does it record the debt indicators and cash cycle (because the company is financed wholly from its own resources).

No additional indicator in this perspective related to the company and / or Internet sector companies is being considered.

\section{Customer perspective}

The prospect of customers is one of those considered the most important for the company, along with the financial perspective. In this case, the company NetRivals considers the standard indicators recorded about customers in a classic BSC to be highly important.

However, the strategic need for the company to get the maximum number of subscriptions (given the strategic importance of the scalability of business) makes it necessary to record a series of complementary indicators that are to do with the strict control of subscriptions ( new customers joining, those leaving, renewals, etc.). Meanwhile, specific indicators are also defined in terms of customer satisfaction with the tool which, given the online nature of the service, are measured by time and frequency of the use made of the tool, as described in the table in Annex 1.

\section{$\underline{\text { Internal process perspective }}$}

Given the characteristics of an Internet company, as in the case of NetRivals, the process perspective is one that needs to record more specific indicators of the sector itself. 
If we look at the traditional indicators of this perspective, it is observed that for this company most of them are fairly unimportant. Therefore, key success factors and internal processes related indicators are closely linked to its own specific operating process for on line subscriptions of the service.

The process of running the business from when a prospective customer is detected until it makes a subscription can be represented as follows in Figure 3:

The company receives a lead (alert) that activates a prospective customer

The company contacts the prospective customer and provides a customized "demo" of their service

The potential customer downloads the "demo"

a trial period of 14 days using the "demo" is offered for free

The customer buys the service by activating a subscription

Figure 3. Operating process of the company NetRivals (Source: self-made)

In response to this process, the indicators needing to register imperatively have to do with the optimization of the times that run at each stage from the beginning (detection of a potential customer) to the purchase or subscription made by the latter.

Also, an indicator that is considered of particular importance is the customization of the service (in this case the custom DEMO offered by the company, depending on the specific characteristics of the company requesting it).

In Annex 1 you can see all the specific indicators that define the company to control this process.

\section{Employee Perspective}

This is the perspective that the company gives less importance to in registering indicators. The only indicators used on the employee level (despite being of medium 
importance for the company at the moment) are the $\%$ sales growth per worker and $\%$ workers who attend to the customers.

The company says that training is required as a quality prerequisite to be able to work in the company, so:

- No training indicators are recorded by the company itself.

- Experience is valued more than studies.

- There are no indicators to measure suggestions put forward by employees. This is because most of the processes are automated and processes that are manual are mostly standardized.

- Nor is there any indication of staff satisfaction.

The qualification of employees (especially in technology and online Marketing) serve as additional indicators which are used by the company.

Bearing in mind the above results, a proposed "strategic map" and "balanced scorecard" for the company NetRivals as tools for improving their management is presented below.

\subsection{The NetRivals Company Strategic Map}

The strategy map identifies the cause-effect relationships between the four perspectives described and key success factors. It is observed that each factor is, in turn, the cause or effect of the following or previous factors according to the direction of the arrows.

In the case of the company NetRivals, and based on the determined strategic plan following the questionnaire obtained by using the balanced scorecard (Annex 1) the key factors of success of the organization are identified and the cause- effect relationship between them is established. A proposed strategic map for the company NetRivals with different key success factors that would make up the four perspectives of the BSC is given in Figure 4. 


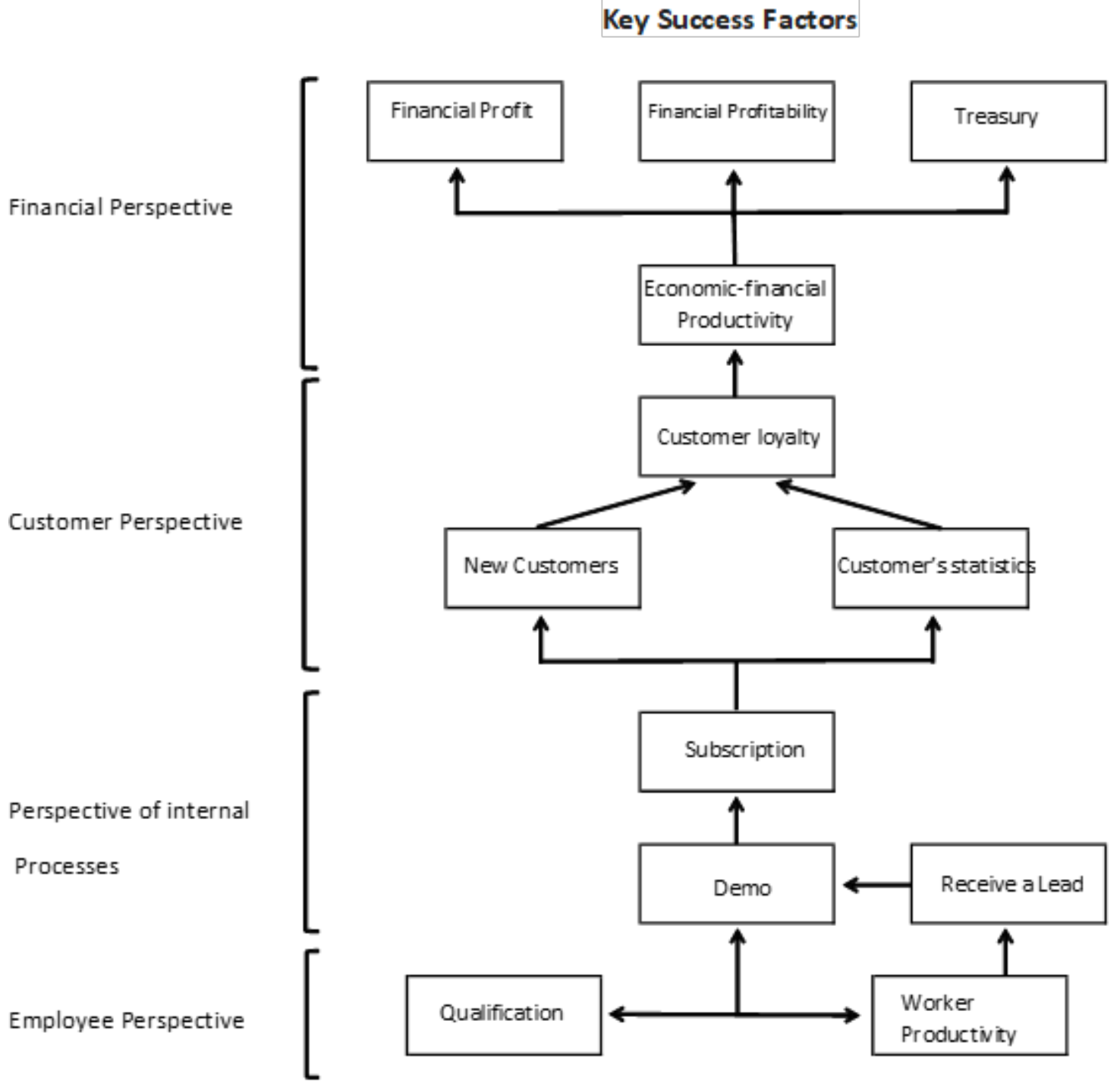

Figure 4. Strategic map Netrivals (Source: Author)

Causal relationships between different perspectives and key success factors in the case of the company NetRivals can be established as follows:

\section{Employee Perspective}

The company believes that recruiting staff with good qualifications at the outset promotes internal input a posteriori. Internal training causes no worry because it is a requirement for recruitment. This qualification is directly correlated with worker productivity.

\section{$\underline{\text { Internal process perspective }}$}

Receiving a Lead (automatic electronic notification of potential customer) may seem a priori an external variable which is subject to the randomness of a potential customer. However, in reality, having qualified staff with high productivity directly 
affects the number of entries (Leads) through use of the daily operations of the marketing department.

In turn, these employees respond in the composition and delivery of a personalized "Demo" quickly so that the potential customer can download it in the shortest possible time and then be offered a 14-day period to use it for free so that in the end an order of purchase or subscription to the service offered is secured.

\section{Customer perspective}

Once the subscription has been obtained the final objective is customer loyalty in the future; to this end special attention to monitoring new customers as well as the statistical control of existing ones is given because this customer perspective is one of the most important for the case study. This concerns us because one of the main objectives of the company Netrivals is to get the maximum number of subscriptions since it is an SAAS service (Software as a service).

\section{Financial perspective}

The increase in the number of loyal customers means an increase in financial- economic productivity measured in terms of sales and market share. This productivity is finally converted into greater financial returns, from the perspective of the shareholder, increased profitability, from the perspective of the company and increased liquidity of the company in monetary terms to safeguard its solvency.

\subsection{The Balanced Scorecard of NetRivals Company}

Once the strategic map has been established, the customized BSC Netrivals Company is designed, in order to establish a management model that helps the organization to transform its strategy into operational objectives.

The most appropriate KPIs are selected in order to have information about all the key success factors of the organization. Once the indicators to be measured, the form of analysis and the periodicity of calculation have been agreed, they should be made extensive to the entire organization to ensure a good implementation of the BSC. In the case of NetRivals, calculation is recommended on a monthly basis in order to analyse their evolution over time. 
Table 2 shows the different key success factors identified in the company NetRivals with its respective measured KPIs (Key Performance Indicators) as proposed for each of the key factors which are structured, in turn, based on the four perspectives discussed in the case study: employees, internal processes, customers and financial.

\section{Employee Perspective}

\section{Key Success Factors}

Qualification

Worker Productivity

\section{KPIs (Key Performance Indicators)}

$=$ Workers with specific training /Total number of workers

\section{Perspective of internal processes}

Key Success Factors

Receive a Lead

Demo

$=$ Arithmetic mean of the number of days between a Lead arrives and the potential customer receives the Demo

$=$ Arithmetic mean of the number of days between the company passes the Demo and the potential customer download

= Downloads / Demo's

$=$ Total specific Demo's for the customer / Total Demo's submitted

Subscription $\quad$ Arithmetic average the number of days between the potential
customer downloads the Demo and makes the subscription
$=$ Total Subscribers / Demo Number
$=$ Investment in R\&D / sales
$=$ Costs of mistakes / sales


$=$ Services delivered within the deadline / Total orders

$=$ Number of claims / service number provided

\section{Customer perspective}

\section{Key Success Factors}

Customer statistics

\section{KPIs (Key Performance Indicators)}

$=$ Absolute value of the number of active monthly subscriptions

$=$ Absolute value of the number of active monthly subscriptions (high)

$=$ Absolute value of the number of unsubscribed subscriptions

$=$ Absolute value of the number of renewed subscriptions

$=$ Proportion of domestic sales / total sales

$=$ BAII / Number of customers
New costumers

$=$ Number of customer's year / number of customers from the previous year

$=($ Number of new customers $/$ number of new companies and $/$ or persons asking)

Customer loyalty

$=$ Returning customers / Total customers

$=$ Average daily time the customer is using the tool

$=$ Average days frequency that the tool is used

\section{Financial Perspective}

\section{Key Success Factors}

Economic-financial productivity

\section{KPIs (Key Performance Indicators)}

$=$ Sales of new markets $/$ Total sales

$=($ Current year sales - previous year sales $) /$ Previous year sales 
$=($ Current year market share - Previous year market share $) /$

Previous year market share

Treasury $\quad=($ Realizable + Available $) /$ Current Liabilities

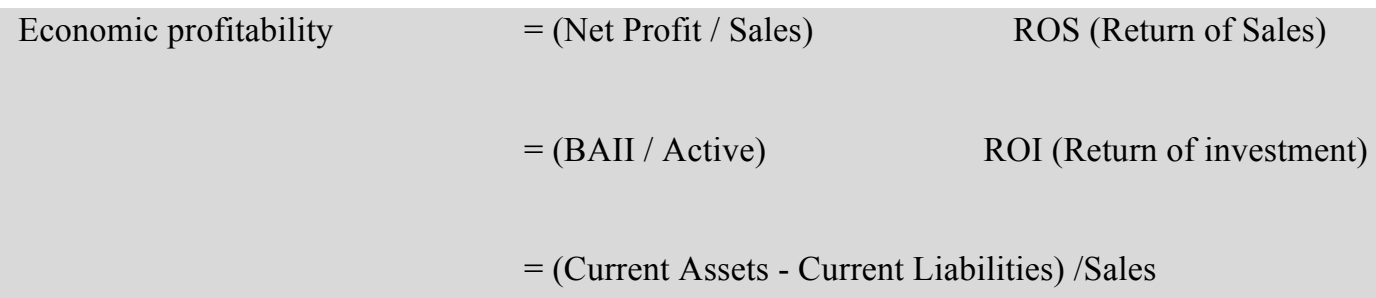

Table 2. Balanced Scorecard of NetRivals (Source: Author)

\section{Conclusions}

After analysing the case of a small business, NetRivals, as an example of a technology startup company in the Internet industry, you can set different conclusions as to their key success factors and KPIs.

First, the need to take into account for the company, key success factors is found for each of the four traditional perspectives BSC established by Kaplan and Norton (1992).

Secondly, as to the traditional perspectives BSC noted that the financial registered in NetRivals, is offered less difference in key success factors and KPIs regarding any other companies in other sectors.

Third, the perspective of specific processes for the operation of Internet companies and their virtual relationship with customers (customer perspective), require the establishment of specific indicators to monitor these processes. The strategy of Internet companies as 
NetRivals is almost always supported by the scalability of the business, since its service is defined as a SAAS (Software as a Service) and needs from a global view of their market in order to capture a huge market share; Thus, you should have a very strict monitoring the process to establish and maintain subscriptions that are the basis for maintaining this market share. In addition, it is essential for these companies, the power of the Internet to offer a high level of customization of its proposal, allowing each user to treat uniquely. This makes constant monitoring of each customer and their virtual interaction with the company needed.

Finally, as to the prospect of people, it is especially essential in NetRivals and therefore could be extrapolated to Internet companies, the need for highly qualified employees, especially in areas such as online marketing and technology.

The BSC designed for case study NetRivals requires a flexibility that allows fit in itself over the time, so that they can vary the KPIs defined in terms of how times change in a competitive industry as technological startup of very small dimensions.

As research for the future, intends to use the case of the company NetRivals as a model to develop critical success and KPIs small business, as NetRivals operate entirely on the Internet factors, and from there to test this model in a representative sample of companies. 


\section{REFERENCES}

Alvarez, I.; Benamou, J.; Fernández-Bosch, J.M.; Solé, C. (2011). España cONecta. Cómo transforma Internet la economía española. The Boston Consulting Group. Inc. Boston. USA.

Amat Salas, O.; Hernández J.M.; Fontrodona, J. y Fontana, I. (2001): El cuadro de mando integral y el crecimiento empresarial. Partida Doble, núm. 126, octubre.

Ballarin, E.; Dávila, A. (1999). El Cuadro de Mando Integral. Documento de trabajo (DT2639), IESE. Universidad de Navarra.

Butler, A.S. (2000) Developing your company's new e-business. The Journal of Business Strategy 21 (6), 38-42.

Cebrián, M. S.; Cer, E. F. (2004). Un análisis de la flexibilidad del Cuadro de Mando Integral (CMI) en su adaptación a la naturaleza de las organizaciones. Revista Iberoamericana de contabilidad de gestión, 2(4), 1-21.

Dubelaar, C.; Sohal, A.; Savic, V. (2005). Benefits, impediments and critical success factors in B2C E-business adoption. Technovation, 25(11), 1251-1262.

Hoque, Z.; James, W. (2000) Linking balance scorecard measures to size and market factors: impact on organizational performance. Journal of Management Accounting Research, Vol. 12, pp. 1-17.

Kaplan, R. S.; Norton, D. P. (1992). The Balanced Scorecard - Measures that Drive performance. Harvard Business Review, 70(1), 71-89.

Kaplan, R.S; Norton, D.S. (2002). Cómo utilizar el Cuadro de Mando Integral. Ediciones Gestión 2000. Barcelona.

Lebas, M. (1994). Managerial Accounting in France; Overview of Past tradition and Current Practice. European Accounting Review, n 3, pp.471-487.

Monte, A. P.; Fontenete, C. (2012) Balanced Scorecard in SMEs-A Proposal for Small Gas Stations in Portugal. World Academy of Science, Engineering and Technology, 66, pp. 266-277.

Naqi, S. (2013) Ratify, Reject or Revise: Balanced Scorecard and Universities. International Journal of Educational Management, 27(3), pp. 1-34.

Phan, D.D. (2001). E-business management strategies: a business-tobusiness case study. Information Systems Management Fall, 61-69.

Porter, M.E. (2001). Strategy and the internet. Harvard Business Review March, 62-78.

Pozo, E. C.; Correa, J. A. A. (2000). La influencia del tamaño, las dimensiones estratégicas y el entorno en la implantación de innovaciones en la organización: Internet 
en las pequeñas y medianas empresas. Investigaciones europeas de dirección y economía de la empresa, 6(2), 91-110.

Rigby, D.K.; Bilodeau, B. (2011) Management Tools \& Trends 2011. Bain \& Company Corporation, Boston, United States. http://www.bain.com/Images/BAIN_BRIEF_Management_Tools.pdf

Rompho, N. (2011): Why the Balanced Scorecard Fails in SMEs: A Case Study. International Journal of Business and Management, 6(11), pp. 39-46.

Tennant, C.; Tanoren, M. (2005). Performance management in SMEs: a Balanced Scorecard perspective. International Journal of Business Performance Management, $7(2)$.

Turban, E.; King, L.J.; Chung, H. (2000). Electronic Commerce: a Managerial Perspective. Prentice Hall, New York.

Voelker, D.E.; Rakich, J.S; French G.R. (2001). The Balanced Scorecard in Healthcare Organizations: a performance measurement and strategic planning methodology. Hospital Topics, vol. 79, nº 3 .

Yin, R. K. (1989). Case study research: Design and methods, revised edition. Applied Social Research Methods Series, 5 


\section{ANNEX 1}

\section{SURVEY ON USING THE BALANCED SCORECARD AND MEASUREMENT INDICATORS IN THE NETRIVALS COMPANY}

\section{USING THE BALANCED SCORECARD}

1. Use your company have a Balanced Scorecard? (NO) $\mathbf{X} \quad(\mathbf{S I})$

2. What year was it implemented in? It is being implemented

3. How was the implementation made? (check one of the following options)

_

By external resources of the company (eg. Consulting firm)

— Through internal resources with the help of external resources

4. What reasons were given for the implantation of a BSC in your company? (Please rate of 1 to 5 the importance; 1 means very low; 5 means very important)

\begin{tabular}{|l|c|c|c|c|c|}
\hline & \multicolumn{3}{|c|}{ Importance } \\
\hline To initiate a process of change within the company & 1 & 2 & 3 & 4 & 5 \\
\hline To increase the number of performance indicators & 1 & 2 & 3 & 4 & 5 \\
\hline To facilitate the integration of business strategy with the financial plans & 1 & 2 & 3 & 4 & 5 \\
\hline $\begin{array}{l}\text { Translation of the corporate vision and the strategy of the company in an } \\
\text { integrated set of objectives and measures }\end{array}$ & 1 & 2 & 3 & 4 & 5 \\
\hline Benchmarking & 1 & 2 & 3 & 4 & 5 \\
\hline $\begin{array}{l}\text { To achieve long-term and visible improvements a balance between short- } \\
\text { term growth }\end{array}$ & 1 & 2 & 3 & 4 & 5 \\
\hline $\begin{array}{l}\text { Other previously unforeseen: } \\
\text { Productivity control and accountability of each department }\end{array}$ & 1 & 2 & 3 & 4 & 5 \\
\hline
\end{tabular}

5. What were the main obstacles during the implementation process of the BSC? (Please rate of 1 to 5 the importance; 1 means very low; 5 means very important)

\begin{tabular}{|l|c|c|c|c|c|}
\hline & \multicolumn{3}{|c|}{ Importance } \\
\hline Difficulty in understanding with external consultants (if the opportunity arises) & 1 & 2 & 3 & 4 & 5 \\
\hline Lack of support of the management team during the implementation process & 1 & 2 & 3 & 4 & 5 \\
\hline Complexity of the implementation in the whole enterprise & 1 & 2 & 3 & 4 & 5 \\
\hline $\begin{array}{l}\text { General lack of understanding by all stakeholders in the process of implementing } \\
\text { the strategy of the company }\end{array}$ & 1 & 2 & 3 & 4 & 5 \\
\hline Difficulty in assigning weights to different perspectives & 1 & 2 & 3 & 4 & 5 \\
\hline $\begin{array}{l}\text { Difficulty in establishing cause and effect relationships between differenen } \\
\text { perspectives }\end{array}$ & 1 & 2 & 3 & 4 & 5 \\
\hline Difficulty in assigning weights measures within each perspective & 1 & 2 & 3 & 4 & 5 \\
\hline Difficulty in quantifying measures for each perspective & 1 & 2 & 3 & 4 & 5 \\
\hline Unclear because of the large number of prospects & 1 & 2 & 3 & 4 & 5 \\
\hline Unclear because of the large number of measures in each perspective & 1 & 2 & 3 & 4 & 5 \\
\hline Lack of support from employees and middle managers & 1 & 2 & 3 & 4 & 5 \\
\hline Lack of resources both time and money & 1 & 2 & 3 & 4 & 5 \\
\hline Others: & 1 & 2 & 3 & 4 & 5 \\
\hline
\end{tabular}

6. What are the perspectives used in the Scorecard of your company and what is its significance? (Please rate of 1 to 5 the importance; 1 means very low; 5 means very important) 


\begin{tabular}{|l|l|l|l|l|l|l|}
\hline & \multicolumn{5}{|c|}{ Importance } \\
\hline Financial perspective & 0 & 1 & 2 & 3 & 4 & 5 \\
\hline Internal process perspective & 0 & 1 & 2 & 3 & 4 & 5 \\
\hline Customers perspective & 0 & 1 & 2 & 3 & 4 & 5 \\
\hline Training and growth perspective & 0 & 1 & 2 & 3 & 4 & 5 \\
\hline Innovation perspective & 0 & 1 & 2 & 3 & 4 & 5 \\
\hline Social responsibility and environmental perspective & 0 & 1 & 2 & 3 & 4 & 5 \\
\hline Competition perspective & 0 & 1 & 2 & 3 & 4 & 5 \\
\hline Supplier perspective & 0 & 1 & 2 & 3 & 4 & 5 \\
\hline Workers' perspective & 0 & 1 & 2 & 3 & 4 & 5 \\
\hline Shareholder perspective & 0 & 1 & 2 & 3 & 4 & 5 \\
\hline Others: & 0 & 1 & 2 & 3 & 4 & 5 \\
\hline
\end{tabular}

7. What is your assessment of the Balanced Scorecard? (Please rate from 1 to 5 valuation tool, 1 means very poor, 5 means very good)

\begin{tabular}{|l|l|l|l|l|l|}
\hline & \multicolumn{5}{|c|}{ Assessment } \\
\hline Assessment of the Balanced Scorecard & 1 & 2 & 3 & 4 & 5 \\
\hline
\end{tabular}

II. INDICATORS AND NON - FINANCIAL COMPANY

(Please rate of 1 to 5 the importance; 1 means very low; 5 means very important)

\begin{tabular}{|c|c|c|c|c|c|c|}
\hline \multirow{2}{*}{$\begin{array}{c}\text { DIMENSION / INDICATOR } \\
\text { 1. Financial Perspective }\end{array}$} & \multicolumn{6}{|c|}{ Importance } \\
\hline & & & & & & \\
\hline$\%$ Sales of new services /Total sales & 0 & 1 & 2 & 3 & 4 & 5 \\
\hline$\%$ Sales from new markets & 0 & 1 & 2 & 3 & 4 & 5 \\
\hline \% Sales Growth (Current-year year earlier) & 0 & 1 & 2 & 3 & 4 & 5 \\
\hline$\%$ Market share growth (current-year year earlier) & 0 & 1 & 2 & 3 & 4 & 5 \\
\hline $\begin{array}{l}\text { Earnings before interest and taxes (EBIT) / Number of } \\
\text { employees }\end{array}$ & 0 & 1 & 2 & 3 & 4 & 5 \\
\hline ROS (Net Profit / Sales) & 0 & 1 & 2 & 3 & 4 & 5 \\
\hline Debt (Total liabilities / Total passive) & 0 & 1 & 2 & 3 & 4 & 5 \\
\hline Cash cycle (days) & 0 & 1 & 2 & 3 & 4 & 5 \\
\hline $\begin{array}{l}\text { Working capital / sales ((Current Assets - Current Passive) / } \\
\text { Sales)) }\end{array}$ & 0 & 1 & 2 & 3 & 4 & 5 \\
\hline ROI (EBIT / Active) & 0 & 1 & 2 & 3 & 4 & 5 \\
\hline ROE (Net profit / Equity) & 0 & 1 & 2 & 3 & 4 & 5 \\
\hline 1.1. Others suggested by the company: & 0 & 1 & 2 & 3 & 4 & 5 \\
\hline Current Active / Current Passive & 0 & 1 & 2 & 3 & 4 & 5 \\
\hline 2. Costumers Perspective & & & & & & \\
\hline Domestic market share (proportion of sales / total sales) & 0 & 1 & 2 & 3 & 4 & 5 \\
\hline $\begin{array}{l}\% \text { Growth of number of customers (No. customers year) / (No. } \\
\text { customers year earlier) }\end{array}$ & 0 & 1 & 2 & 3 & 4 & 5 \\
\hline Average customer profitability (EBIT / (No. customers) & 0 & 1 & 2 & 3 & 4 & 5 \\
\hline $\begin{array}{l}\text { Attracting new customers (number of new customers / number } \\
\text { of new businesses and / or individuals who ask) }\end{array}$ & 0 & 1 & 2 & 3 & 4 & 5 \\
\hline Customer loyalty ( $\%$ of customers who return to buy) & 0 & 1 & 2 & 3 & 4 & 5 \\
\hline $\begin{array}{l}\text { Customer satisfaction (customer satisfaction survey results, note } \\
10 \text { ) }\end{array}$ & 0 & 1 & 2 & 3 & 4 & 5 \\
\hline Returns / total sales & 0 & 1 & 2 & 3 & 4 & 5 \\
\hline
\end{tabular}




\begin{tabular}{|c|c|c|c|c|c|c|}
\hline 2.1. Others suggested by the company: & & & & & & \\
\hline Total number of monthly active subscriptions & 0 & 1 & 2 & 3 & 4 & 5 \\
\hline New monthly subscriptions (high) & 0 & 1 & 2 & 3 & 4 & 5 \\
\hline Low monthly subscription (churn rate) & 0 & 1 & 2 & 3 & 4 & 5 \\
\hline Subscription renewals & 0 & 1 & 2 & 3 & 4 & 5 \\
\hline Daily time you are using the tool (customer satisfaction) & 0 & 1 & 2 & 3 & 4 & 5 \\
\hline Frequency of days when the tool is used (customer satisfaction) & 0 & 1 & 2 & 3 & 4 & 5 \\
\hline \multicolumn{7}{|l|}{ 3. Perspective of internal processes } \\
\hline$\% \mathrm{R} \& \mathrm{D}$ expenditure / sales & 0 & 1 & 2 & 3 & 4 & 5 \\
\hline Number of new products per year & 0 & 1 & 2 & 3 & 4 & 5 \\
\hline Maturation cycle in days (days of stock + collection period) & 0 & 1 & 2 & 3 & 4 & 5 \\
\hline Costs of non-quality sales (error costs / sales) & 0 & 1 & 2 & 3 & 4 & 5 \\
\hline Services delivered on time / total orders & 0 & 1 & 2 & 3 & 4 & 5 \\
\hline Average collection period & 0 & 1 & 2 & 3 & 4 & 5 \\
\hline$\%$ of unpaid sales & 0 & 1 & 2 & 3 & 4 & 5 \\
\hline Claims number / number of orders or services supplied & 0 & 1 & 2 & 3 & 4 & 5 \\
\hline \multicolumn{7}{|l|}{ 3.1. Others suggested by the company : } \\
\hline Number of leads received & 0 & 1 & 2 & 3 & 4 & 5 \\
\hline $\begin{array}{l}\text { There comes a time between LEAD until a product demo is } \\
\text { passed to potential customer }\end{array}$ & 0 & 1 & 2 & 3 & 4 & 5 \\
\hline $\begin{array}{l}\text { Time between the DEMO and potential customer spends } \\
\text { download }\end{array}$ & 0 & 1 & 2 & 3 & 4 & 5 \\
\hline $\begin{array}{l}\text { Time between the potential customer has downloaded the } \\
\text { DEMO and makes subscription }\end{array}$ & 0 & 1 & 2 & 3 & 4 & 5 \\
\hline$\%$ of downloads / DEMOs & 0 & 1 & 2 & 3 & 4 & 5 \\
\hline$\%$ Subscriptions / DEMO (\% conversion) & 0 & 1 & 2 & 3 & 4 & 5 \\
\hline Customizing Service (DEMO for specific customer) & 0 & 1 & 2 & 3 & 4 & 5 \\
\hline \multicolumn{7}{|l|}{ 4. Perspective employees } \\
\hline Workers survey results & 0 & 1 & 2 & 3 & 4 & 5 \\
\hline Median years of workers in the enterprise & 0 & 1 & 2 & 3 & 4 & 5 \\
\hline$\%$ Sales growth per worker & 0 & 1 & 2 & 3 & 4 & 5 \\
\hline$\%$ Workers abide customers & 0 & 1 & 2 & 3 & 4 & 5 \\
\hline $\begin{array}{l}\% \text { Workers with real-time access to all information of the } \\
\text { company }\end{array}$ & 0 & 1 & 2 & 3 & 4 & 5 \\
\hline Number of suggestions received annual & 0 & 1 & 2 & 3 & 4 & 5 \\
\hline $\begin{array}{l}\text { Number of suggestions made by workers that have been } \\
\text { implemented }\end{array}$ & 0 & 1 & 2 & 3 & 4 & 5 \\
\hline Medium absenteeism and worker days per year & 0 & 1 & 2 & 3 & 4 & 5 \\
\hline$\%$ Senior managers assessed at scorecard & 0 & 1 & 2 & 3 & 4 & 5 \\
\hline $\begin{array}{l}\% \text { MANAGERS DIRECTLY workers evaluated by the } \\
\text { scorecard }\end{array}$ & 0 & 1 & 2 & 3 & 4 & 5 \\
\hline$\%$ Workers who have received training & 0 & 1 & 2 & 3 & 4 & 5 \\
\hline$\%$ Workers with higher education (third grade) & 0 & 1 & 2 & 3 & 4 & 5 \\
\hline \multicolumn{7}{|l|}{ 4.1. Others suggested by the company: } \\
\hline Employee training & 0 & 1 & 2 & 3 & 4 & 5 \\
\hline
\end{tabular}

